\title{
Remdesivir e lopinavir/ritonavir frente ao novo coronavírus: breve revisão
}

\author{
Lara Beatriz Ferreira, Daniela Fernandes Ramos*
}

Núcleo de Desenvolvimento de Novos Fármacos (NUDEFA), Faculdade de Medicina,

Universidade Federal do Rio Grande - FURG, Rio Grande, RS - Brasil

Histórico do Artigo

Recebido em:

05/06/2020

Aceito em:

14/06/2020

Palavras-chave: COVID-19; terapia; antimicrobianos; antivirais

Keywords:

COVID-19; therapy; antimicrobial; antivirals

\begin{abstract}
RESUMO
O novo vírus, denominado SARS-CoV-2, causador da COVID-19, demonstrou alta capacidade de transmissibilidade e infectividade. Devido à inexistência de uma vacina e tratamentos específicos para a COVID-19, até o momento, as pesquisas e estudos clínicos têm redirecionado medicamentos já avaliados frente a outras doenças, para o combate do novo coronavírus. Alguns medicamentos que possam ser promissores no combate de doenças virais, têm sido alvo de estudos devido aos avanços técnico-científicos em relação aos seus mecanismos de ação e dos resultados experimentais e clínicos já obtidos, como é o caso dos fármacos Remdesivir, Lopinavir e Ritonavir. Esse trabalho teve como objetivo realizar uma revisão breve na literatura científica, incluindo estudos que abordassem antivirais como possíveis fármacos promissores no combate ao SARS-CoV-2. Nesse sentido, diante dos estudos analisados, foi demonstrado que os resultados do uso de Remdesivir frente à COVID-19 se mostraram candidatos para o tratamento da SARS-CoV-2. Já os antivirais Lopinavir/Ritonavir, parecem ter eficácia contra o SARS-CoV-2, além do que, quando associados a outros medicamentos, também podem ser efetivos contra doenças causadas por coronavírus. Mesmo com evidências científicas quanto a possibilidade de reposicionar alguns destes antivirais como alternativa farmacológica no manejo dos casos desta pandemia causada por SARS-CoV-2, são necessárias maiores investigações pré-clínicas e clínicas para nortear o uso destes compostos como estratégias terapêuticas frente a esta nova pandemia.
\end{abstract}

Remdesivir e lopinavir/ritonavir in the new coronavírus combat: a short review

\section{ABSTRACT}

The new virus, called SARS-CoV-2, causative agent of COVID-19, has high capacity of transmissibility and infectivity. Due to inexistence of a vaccine and specific treatments for the COVID19, until now, researches and clinical studies have directed drugs, already evaluated against other diseases, to combat the new coronavirus. Some drugs that can be promising against viral diseases, have been the subject of studies due to greater knowledge of their mechanisms of action and positive experimental and clinical results, as is the case of the drugs Remdesivir, Lopinavir and Ritonavir. This study has as objective to create a short scientific review, including studies about these antivirals as promising pharmaceutical compounds against SARS-CoV-2. In this sense, in view of the research and clinical studies analyzed, it was demonstrated that the use of Remdesivir in the treatment of COVID19 have shown were candidates for the treatment of SARS-CoV-2. Meanwhile, the antivirals Lopinavir/Ritonavir, had shown efficacy against SARS-CoV-2, moreover when combined with others medications, it has also shown efficacy against diseases caused by coronaviruses. Even with scientific evidence regarding the possibility of repositioning some of these antivirals as a pharmacological alternative in the management of cases caused by SARS-CoV-2, further research is needed to advance pre-clinical and clinical trials to guide the use of these compounds as therapeutic strategies in the face of this new pandemic.

\section{Introdução}

Coronavírus são vírus pertencentes à família Coronaviridae e à ordem Nidovirales, que podem causar doenças respiratórias e gastrointestinais em humanos (1). Dois coronavírus foram agentes etiológicos identificados por causarem epidemias, em 2003 o vírus

\footnotetext{
* Autor correspondente: danielaramos@ furg.br (Ramos D.F.)
} 
conhecido como causador da síndrome respiratória aguda grave (SARS-CoV) infectou mais de 8.000 pessoas, resultando em uma taxa de mortalidade de $10 \%$ e em 2012 o vírus da síndrome respiratória do Oriente Médio (MERS-CoV) atingiu mais de 27 países e teve uma taxa de mortalidade de $34 \%$ (2-4).

Em dezembro do ano de 2019, foram relatados pacientes com pneumonia de causa desconhecida, na cidade de Wuhan, na China. Após coleta de amostras e diagnósticos laboratoriais foi descoberto um novo coronavírus da subfamília Betacoronavírus nomeado inicialmente de 2019-nCoV $(5,6)$ De acordo com a filogenia, taxonomia e prática estabelecida, reconheceu-se formalmente esse novo vírus como um filogeneticamente relacionado ao SARS-CoV e renomeou-o como coronavírus 2 da síndrome respiratória aguda (SARS-CoV-2) (7).

Até o dia 2 de junho, 2020, o número de indivíduos infectados foi de 6.287.771, com 379.941 mortes confirmadas, no mundo (8). Em 11 de março de 2020 a Organização Mundial da Saúde (OMS) declarou a doença (COVID-19) como uma emergência de saúde pública global e ela passou a ser considerada uma pandemia. Uma das preocupações em relação à doença é a falta de descrição do espectro clínico, bem como o padrão de letalidade, mortalidade, infectividade e transmissibilidade do vírus. Os pacientes infectados podem apresentar sintomas em diferentes graus, a maioria dos adultos ou crianças tem sintomas leves de gripe (febre, mal-estar e tosse), já idosos e pessoas com doenças subjacentes, o quadro clínico pode ser crítico e desenvolver complicações como a síndrome do desconforto respiratório agudo, arritmia, choque, lesão renal aguda, lesão cardíaca aguda, disfunção hepática e infecção secundária $(6,9)$.

No momento existem vários estudos pré-clínicos e clínicos sendo realizados, no intuito de identificar potenciais tratamentos, uma vez que ainda não há vacina para a SARSCoV-2 e a terapêutica ideal dos pacientes infectados não foi estabelecida, sendo assim de suporte e inespecífica para o vírus. A maioria dos estudos abordam a manipulação de fármacos já utilizados, redirecionando-os para o possível tratamento da COVID-19.

Assim, medicamentos utilizados para outras doenças virais, como HIV, Ebola, síndrome respiratória do Oriente Médio (MERS) e síndrome respiratória aguda grave (SARS) têm sido alvos de estudos, uma vez que seus mecanismos de ação já são conhecidos, podendo ter algum impacto no ciclo de vida do novo coronavírus, além de já serem descritas informações relativas à segurança do uso desses fármacos. Devido a urgência em se descobrir possíveis tratamentos para SARS-CoV-2, pesquisas sobre o tema são realizadas e publicadas diariamente. Dessa forma, esse estudo visa fazer uma breve revisão acerca do uso de antivirais no combate à doença, a fim de facilitar o acesso à informação.

\section{Materiais e Métodos}

Foi realizada busca no banco de dados científicos PubMed e no banco de dados, disponibilizado pela OMS, de estudos experimentais (pré-clínicos e clínicos) relacionados à COVID-19, utilizando as seguintes palavras-chaves: "antivirais (e em inglês antiviral)" e "COVID-19", associadas. A pesquisa foi realizada contemplando todos os artigos publicados até 7 de junho de 2020.

\subsection{Critérios de inclusão}

Somente os artigos que utilizassem as abordagens pré-clínicas (in sílico, in vitro, in vivo) e ensaios clínicos de compostos com atividade antiviral anterior e propostos para serem reposicionados frente a COVID-19, foram incluídos na análise desse trabalho. Ademais, foram incluídos apenas artigos nos idiomas português, espanhol e inglês. 


\subsection{Critérios de exclusão}

Os artigos que não atendiam aos critérios de inclusão foram excluídos deste estudo. Desse modo, os artigos foram excluídos pelos seguintes critérios: artigos de revisão, não disponíveis na íntegra e publicados em outro idioma que os não propostos acima.

\subsection{Seleção de artigos e extração de dados}

Todos os artigos encontrados utilizando os descritores foram inicialmente avaliados de acordo com seus resumos. Contudo, quando os resumos não eram suficientes para seleção do estudo foi utilizado o texto na íntegra. Após a identificação de todos os estudos, uma pré-seleção dos artigos foi realizada analisando o objetivo central da revisão e os critérios previamente definidos de inclusão.

Os artigos foram lidos por dois pesquisadores e foi elaborado um instrumento contendo as seguintes categorias: autor/ano da publicação, metodologia, antiviral avaliado e principais resultados encontrados, o qual permitiu a seleção de três antivirais como os mais encontrados e discutidos na literatura científica: Remdesivir, Lopinavir e Ritonavir.

\section{Resultados e Discussão}

Recentemente, diferentes intervenções têm sido reavaliadas para validar uma terapêutica eficaz e consistente para o tratamento do agente etiológico dessa trágica pandemia causada pelo vírus SARS-CoV-2. Uma das principais estratégias a fim de reduzir o tempo de desenvolvimento de um novo fármaco e minimizar os danos que a alta transmissibilidade deste vírus poderá causar a longo prazo para a sociedade como um todo, têm sido o redirecionamento de drogas já disponíveis ou em desenvolvimento para tratar outras doenças.

Nesse contexto, os principais protocolos terapêuticos têm recomendado o uso de agentes antimicrobianos, especialmente antivirais, porém, os fármacos antimaláricos, cloroquina e hidroxicloroquina, tomaram a frente das publicações, emergindo como importante estratégia e têm sido alvos de diversos estudos relacionados a sua ação individual e combinada com outros agentes antivirais e/ou anti-inflamatórios e corticosteroides (1012)

Nesse trabalho, foram encontrados artigos publicados desde 4 de fevereiro de 2020 até o dia 07 de junho de 2020, demonstrando a emergência da temática e a resposta científica à demanda urgente em desenvolver alternativas terapêuticas para essa doença pandêmica. Em suma, os estudos encontrados ressaltam apenas uma pequena parcela dos antivirais existentes e que poderiam ser estudados como possíveis agentes no combate ao novo coronavírus. Entre eles podemos destacar diversos análogos de nucleosídeos, tais como Remdesivir e Ganciclovir, e alguns inibidores enzimáticos de processos biossintéticos virais, Lopinavir/Ritonavir (LPV/r), Oseltamivir, Ribavirina (13). Dessa forma, apresentamos abaixo os três principais antivirais que tem sido foco em investigações terapêuticas para o possível tratamento da COVID-19: Remdesivir, Lopinavir e Ritonavir.

\subsection{Remdesivir}

\subsubsection{Contexto}

O fármaco Remdesivir foi desenvolvido, em 2009, pela empresa Gilead Sciences, 
sediada na Califórnia, por meio de pesquisas em andamento em hepatite C (HCV) e vírus sincicial respiratório (RSV), desde então, recebeu um destaque maior, e em 2013 e 2014 os estudos do perfil do composto sugeriram potencial atividade antiviral de amplo espectro. Esse composto é um pró-fármaco análogo ao nucleotídeo adenosina, inibindo a replicação viral, redirecionando a RNA polimerase RNA dependente (RdRp) e, dessa forma, seu principal metabólito é incorporado nas novas cadeias de RNA formadas pelo vírus, o que resulta em uma interrupção antecipada do produto genético viral (14).

O Remdesivir, até a data em que este estudo foi conduzido, não era um medicamento aprovado, pelos órgãos regulamentadores, para comercialização, porém, devido às evidências científicas, tem sido liberado pelo Food and Drug Administration (FDA) para uso em estudos clínicos. O composto é reconhecido, por meio de estudos in vitro e in vivo, por ser um promissor antiviral contra várias famílias de vírus incluindo Filoviridae (Ebola) e Coronaviridae (MERS-CoV e SARS-CoV). Warren et al. (14) identificaram a atividade antiviral do Remdesivir em macacos Rhesus infectados com o vírus EBOV, causador da doença Ebola. Nesse estudo, houve administração intravenosa única e diária de $10 \mathrm{mg}$ do fármaco por 12 dias, o que resultou em uma supressão da replicação viral e melhora dos sinais clínicos e fisiopatológicos, mesmo quando a dose foi administrada três dias após a exposição ao EBOV (14).

Wit et al. (15) também demonstraram a eficácia do composto na profilaxia e tratamento com o Remdesivir em um modelo de macaco Rhesus, porém infectado por MERS-CoV. Nesse modelo, o uso de $5 \mathrm{mg} / \mathrm{kg}$ deste fármaco iniciado 24 horas antes da inoculação do vírus, e o uso de $5 \mathrm{mg} / \mathrm{kg}$ iniciado 12 horas após a inoculação do vírus, causou redução na carga viral em diversos órgãos do sistema respiratório, quando comparado aos animais controles. Além disso, não houve detecção de RNA viral nos tecidos renais dos animais tratados e foi observado diminuição na doença pulmonar e os sinais clínicos de infecção, em comparação ao tratamento com veículo (15).

Para mais, Sheahan et al. (16) demonstraram, em um modelo murino infectado por MERS-CoV, que doses profiláticas e terapêuticas de Remdesivir $(25 \mathrm{mg} / \mathrm{kg})$ causaram uma melhora na função respiratória e redução, em aproximadamente $100 \%$ da carga viral, quando realizados testes, in vitro, em linhagens celulares (Calu-3) (13). Ademais, em um modelo de camundongo infectado com SARS-CoV, Sheahan et al (14) administraram doses, via subcutânea, profiláticas e terapêuticas precoces, de 2,79 $\mu \mathrm{M}$ de Remdesivir e detectaram redução significativa na carga viral pulmonar e melhora nos sinais clínicos da doença, incluindo a função respiratória (16).

É importante destacar que uma dificuldade encontrada em desenvolver fármacos contra vírus como SARS-CoV é a ação da proteína exonuclease (ExoN), capaz de extrair análogos de nucleotídeos incorporados ao RNA viral e, assim, promover resistência a possíveis antivirais (17).

\subsubsection{Remdesivir x COVID-19}

Shannon et al. (18) mostraram resultados promissores, in sílico, em relação ao Remdesivir, uma vez que a incorporação de análogos de nucleotídeos no material genético do SARS-CoV-2 parece ser mais rápida do que a excisão pela exonuclease viral, demonstrando o potencial do Remdesivir em inibir a replicação do vírus e sua potencialidade em ser mais efetivo do que a ação da exonuclease (ExoN) (18).

No estudo experimental, in vitro, de Wang et al. (19), o Remdesivir obteve efeito em inibir potencialmente o vírus em baixa concentração (Concentração Efetiva para Inibir $50 \%$ da carga viral - EC50 $=0,77 \mu \mathrm{M}$ ) e apresentou alto índice de seletividade (IS) quando comparada a citotoxicidade em células Vero E6 (IS >129,87), além de inibir a 
infecção pelo vírus em uma linhagem de câncer de fígado humana (Huh-7). Nesse estudo experimental, concluíram que o fármaco atua após a entrada do vírus na célula, interferindo em algum mecanismo que impeça a multiplicidade viral, e acreditam na sua atuação como análogo de nucleotídeo, já descrito em outras doenças (19).

Já no estudo realizado por Beck et al. (20), por meio de interação fármaco-alvo em um modelo 3D Molecule Transformer-Drug Target Interaction (MT-DTI), foi previsto que o Remdesivir se liga a proteinase $3 C$-like do complexo de replicação do SARS-CoV-2, com constante de dissociação $\left(\mathrm{K}_{\mathrm{D}}\right)$ de 113,13 nM (18). Outro estudo avaliou, através de docagem molecular, a energia de ligação entre compostos inibidores de nucleotídeo e RdRp de coronavírus, demonstrando que o Remdesivir, apresenta importante competição com o sítio ativo da enzima viral (de - 6,5 a 9,0 kcal/mol), o que corrobora com os estudos já citados quanto a sua potencialidade como alternativa terapêutica para tratar COVID19 (18). Além disso, o sucesso terapêutico da combinação com Emetina foi proposto por Choy et al. (29), uma vez que em seus resultados foi avaliada a interação do Remdesivir $(6,25 \mu \mathrm{M})$ com Emetina $(0,195 \mu \mathrm{M})$ resultando em $64,9 \%$ de inibição viral, demonstrando que pode haver sinergismo entre os dois compostos a partir dessas concentrações (20).

Devido aos resultados promissores alcançados, o fármaco tem sido utilizado de maneira compassiva para possível tratamento de pacientes com SARS-CoV-2. Grein et al. (21), descreveram a melhora clínica de 36 dos 53 pacientes infectados hospitalizados, todos receberam, durante 10 dias, doses do composto, sendo $200 \mathrm{mg}$ administrados por via intravenosa no dia 1, seguidos por $100 \mathrm{mg}$, diariamente, nos nove dias restantes de tratamento (21). Além disso, Holshue et al. (22) relataram o primeiro caso confirmado de SARS-CoV-2 nos Estados Unidos, em Washington, no dia 19 de janeiro de 2020. O paciente relatou tosse e febre e revelou ter feito uma viagem para Wuhan, China, tendo o teste para SARS-CoV-2 positivo. O tratamento nos primeiros dias de internação foi de suporte e nos dias seguintes o quadro evoluiu para uma pneumonia, com necessidade de suplementação de oxigênio. Foi feito, então, o uso do Remdesivir e nenhuma reação adversa foi observada, apresentando evolução clínica positiva, com a melhora no quadro respiratório e febre (22).

Durante-Mangoni et al. (23) descreveram a evolução clínica de quatro pacientes infectados com SARS-CoV-2 em estado grave que receberam 200 mg de Remdesivir, por via intravenosa, no primeiro dia, seguido de $100 \mathrm{mg}$ por até 10 dias. Todos os pacientes haviam feito uso de outros medicamentos anteriormente, como Lopinavir/Ritonavir (LPV/r) e Hidroxicloroquina, porém foram interrompidos para ser iniciado o tratamento com Remdesivir. Foi observado um aumento na contagem de linfócitos de todos os pacientes e o resultado do exame de swab nasal tornou-se negativo em três, dos quatro pacientes, após três dias de terapia, apesar disso, um paciente foi a óbito por falência múltipla de órgãos. Em conclusão, o estudo é limitado pelo baixo número de indivíduos e heterogeneidade dos tratamentos, porém os autores o consideram relevante para outros estudos clínicos (23).

Desse modo, estudos pré-clínicos e relatos de caso que demonstram a potencialidade do Remdesivir em conter SARS-CoV-2 encorajaram ensaios clínicos randomizados. A empresa Gilead Sciences, em 6 de março de 2020, iniciou os testes para avaliar a segurança e eficácia do composto em 6000 pacientes infectados com SARS-CoV-2, em situação grave e que utilizavam, ou não, respiradores (24). Além disso, Wang et al (25) em um estudo randomizado, duplo-cego e placebo-controlado, realizado em dez hospitais em Hubei, China, avaliou o uso de Remdesivir em pacientes infectados por SARS-CoV2 em estado grave. Nesse sentido, houve a divisão aleatória dos pacientes em dois grupos, sendo que um receberia $200 \mathrm{mg}$ de Remdesivir intravenoso no primeiro dia e $100 \mathrm{mg}$ do 
segundo até o décimo dia, já o segundo grupo receberia a mesma quantidade de infusões, porém de placebo. Em seus resultados, concluíram que o uso do Remdesivir não foi associado a uma diferença no tempo de melhora clínica. Além disso, eventos adversos foram relatados em $66 \%$ dos indivíduos que fizeram uso de Remdesivir e em $64 \%$ indivíduos com que fizeram uso de placebo (25).

Para mais, o Instituto Nacional de Alergia e Doenças Infecciosas (NIAID) dos EUA está patrocinando um estudo controlado iniciado em 21 de fevereiro de $2020 \mathrm{com}$ previsão de término em 2023, em que pacientes hospitalizados com o novo coronavírus são designados em receber infusões de Remdesivir ou placebo, além de tratamento de suporte, se necessário (26). Goldman et al (27), conduziram um estudo randomizado de fase 3, com 397 pacientes infectados por SARS-CoV-2 e que estavam há quatro dias hospitalizados em 55 hospitais de diferentes países. Os pacientes foram divididos em dois grupos, sendo assim 200 indivíduos fizeram uso do Remdesivir durante 5 dias e 197 durante 10 dias. Todos os pacientes receberam $200 \mathrm{mg}$ do fármaco no primeiro dia de tratamento e $100 \mathrm{mg}$ nos dias subsequentes. Após análise dos dados os autores concluíram que não houveram diferenças no quadro clínico quando comparado os grupos (27).

As evidências da eficácia do Remdesivir, a partir de ensaios pré-clínicos, muitas vezes limitados, como opção terapêutica para o tratamento da COVID-19, demonstram que esse fármaco ainda necessita ser melhor estudado e avaliado, para que seu uso em humanos seja seguro. Além disso, para que haja sua aprovação pelos órgãos regulamentadores para fins terapêuticos frente a infecções virais como as que tem acometido a humanidade recentemente, há necessidade de mais ensaios clínicos de fase III, com sucesso.

Ademais, os investimentos das empresas farmacêuticas em comercializar e/ou investigar agentes terapêuticos contra coronavírus têm sido restritos ao período em que há uma grande demanda pelos medicamentos, ou seja, durante os surtos. Sendo assim, há inviabilização dos avanços nos ensaios clínicos, pela reduzida proporção de indivíduos doentes que possam reafirmar a eficácia no tratamento da epidemia, quanto na falta de mercado global significativo para retorno do investimento realizado pelas industrias (28).

\subsection{Lopinavir e Ritonavir}

\subsubsection{Contexto}

O Ritonavir é um inibidor sintético de protease do vírus da Imunodeficiência Humana Adquirida (HIV) e foi aprovado pelo FDA, dos Estados Unidos, entre 1995 e 1997 (29). O mecanismo antiviral desse fármaco envolve a sua ligação ao sítio ativo da protease do HIV, impedindo o processamento e maturação viral, além do que os produtos virais na presença do composto são imaturos e não infecciosos (30).

Outro inibidor desta enzima importante na produção de vírus maduros, que merece destaque é o Lopinavir, o qual tem como principal ação, a prevenção da propagação viral em células ainda não infectadas, não possuindo efeito em células com o material genético viral já integrado (31). Assim como os outros antivirais, Lopinavir e Ritonavir, também foram alvo de estudos para o combate de doenças provocadas pelos coronavírus.

Wu et al. (32) avaliaram 10.000 compostos em células Vero E6 infectadas com SARS$\mathrm{CoV}$, entre os quais estavam inclusos Ritonavir e Lopinavir. Apenas 50 compostos foram capazes de impedir o efeito citopatogênico com uma concentração de $10 \mu \mathrm{M}$, entre os quais não estavam os dois antirretrovirais destacados nesta seção (32). Entretanto, um estudo, feito por Wilde et al (33), examinou 384 fármacos aprovados pelo FDA para verificar se havia atividade antiviral, in vitro, contra MERS-CoV, e identificaram que o composto Lopinavir inibia $50 \%$ da replicação viral em baixas concentrações $\left(\mathrm{EC}_{50}=3 \mathrm{a}\right.$ 
$8 \mu \mathrm{M}$ ), ademais, observaram uma inibição viral de $89 \%$ na dose de $12 \mu \mathrm{M}$ (33).

Sabe-se que o genoma da SARS-CoV codifica duas poliproteínas, ppla e pplb, que são clivadas em diferentes proteínas importantes na estrutura e no metabolismo viral. Este processo é realizado por uma protease chamada protease principal (Main proteae - Mpro) ou protease do tipo 3C (3C-like protease-3CLpro), assim, a Mpro é um alvo ideal para o design e desenvolvimento de fármacos. Nesse sentido, Dayer et al. (34), avaliaram a interação de nove inibidores de protease do vírus HIV-1, aprovados pelo FDA, com Mpro para ajudar a projetar inibidores mais eficazes em SARS-CoV, já que suas proteases principais são semelhantes. Nesse estudo, in silico, verificaram que o Lopinavir apresentou maior eficiência em se ligar no sitio ativo da protease viral (menor energia de ligação $=-413,99$ ), com redução na flexibilidade da enzima e melhor acoplamento na protease Mpro, indicando melhor eficácia do Lopinavir como inibidor deste alvo em relação aos outros compostos avaliados (34).

A associação entre os dois inibidores de protease (Lopinavir e Ritonavir) utilizados para o tratamento da infecção pelo HIV em adultos, adolescentes e crianças, de acordo com as diretrizes norte-americanas e britânicas, deu origem a um fármaco aprovado pelo FDA, dos Estados Unidos, há 20 anos, desenvolvido a fim de garantir a eficácia da terapia combinada entre os dois medicamentos (35). Isso se deve ao fato de que, quando juntos, o Ritonavir inibe o complexo enzimático que contribui para metabolização do Lopinavir (citocromo P450), aumentando a meia-vida do mesmo, ou seja, seus níveis plasmáticos e garantindo uma maior ação sobre a protease viral 3CLpro, já descrita por ser importante no metabolismo viral (31).

Esta combinação tem sido alvo de estudos para análise de possível atividade antiviral frente a SARS-CoV e MERS-CoV. Sheahan et al. (36), avaliaram a atividade antiviral contra MERS-CoV, in vivo e in vitro, dos compostos antivirais (Lopinavir, Ritonavir e Remdesivir) e imunomoduladores (Interferon $\alpha 2 \mathrm{a} / 2 \mathrm{~b}$ e Interferon- $\beta$ ). Em uma análise comparativa, demonstraram que a combinação LPV/r + Interferon $\beta$ (razão molar de 4,6/1 e 1 unidade internacional / $\mathrm{mL}$ de Interferon $\beta$ ), quando administrado profilaticamente reduz ligeiramente as cargas virais e quando administrado terapeuticamente melhora a função e hemorragia pulmonar (36).

Em 2003, Chu et al. (37), conduziram um estudo clínico no United Christian Hospital e no Caritas Medical Center, em Hong Kong. Participaram 152 pacientes internados até o dia 16 de abril de 2003 com SARS-CoV e que foram tratados com Ribavirina durante 14 dias e serviram como controle histórico do estudo $(n=111)$, já os pacientes diagnosticados após essa data foram tratados com Lopinavir (400 mg) / Ritonavir (100 mg) a cada 12 horas por 14 dias $(\mathrm{n}=41)$ além de Ribavirina. Após análise dos resultados, verificaram que a Síndrome de Desconforto Respiratório Agudo, foi menor no grupo que utilizou LPV/r com Ribavirina (1/41) do que nos controles (32/111) (37).

Além disso, um relato de caso, descrito por Kim et al. (38), demonstrou o progresso clínico de um paciente de 64 anos infectado com MERS-CoV e tratado com a combinação de Lopinavir $400 \mathrm{mg}$ / Ritonavir $10 \mathrm{mg}$ (administrados 2 vezes ao dia), Ribavirina (dose inicial de $2,0 \mathrm{~g}$, seguida por $1,2 \mathrm{~g}$, três vezes por dia) e interferon- $\beta$ (injeção subcutânea, $180 \mu \mathrm{g} / 0,5 \mathrm{ml}$ ). Após 6 dias de tratamento antiviral, o paciente teve resultado negativo para MERS-CoV e recebeu alta no $13^{\circ}$ dia, contados a partir da admissão, devido a sua recuperação completa (38). Esses achados podem sugerir que a combinação de LPV/r a outro medicamento pode ser mais eficaz contra os coronavírus SARS-CoV e MERS-CoV (38).

\subsubsection{Lopinavir e Ritonavir x COVID-19}


Beck et al. (20), por meio de ensaios, in silico, previram possíveis fármacos que poderiam atuar contra o novo coronavírus. Seus resultados indicaram uma afinidade do composto Lopinavir à helicase da SARS-CoV-2 $\left(K_{d=}=78,49 \mathrm{nM}\right)$ ocupando a posição $295^{\circ}$ de 3411 compostos analisados em relação à helicase, o que poderia sugerir um melhor potencial em impedir a replicação viral (20)

Além disso, Kang et al. (39) em um estudo in vitro, avaliaram a utilização do Lopinavir ( $7 \mu \mathrm{g} / \mathrm{mL})$ e Ritonavir $(1,75 \mu \mathrm{g} / \mathrm{mL})$ e/ou da Hidroxicloroquina ( $1 \mathrm{ou} 2 \mu \mathrm{g} / \mathrm{mL}$ ) em células Vero, uma hora após a inoculação do SARS-CoV-2. Em seus resultados, após 48 horas, foi observado que as células tratadas com Lopinavir e Ritonavir tiveram menores efeitos citopatológicos em comparação às tratadas somente com Hidroxicloroquina e a combinação de Lopinavir e Ritonavir + Hidroxicloroquina. A quantificação do RNA viral foi avaliada e demonstrou redução da carga viral quando utilizado Lopinavir e Ritonavir diferentemente de quando foi utilizada somente a Hidroxicloroquina, a qual não houve diferenciação sobre o grupo controle (39).

Nesse segmento, em um estudo retrospectivo, Wu et al. (40) descreveram o progresso clínico de 280 pacientes internados em quatro hospitais de Jiangsu e Província de Anhui, na China, que estavam infectados com SARS-CoV-2. Todos os pacientes fizeram uso dos antivirais Ribavirina, Lopinavir ou Ritonavir e foi constatado que pacientes em condições leves que fizeram uso precoce do tratamento antiviral, tiveram redução significativa na progressão da doença (40). Entretanto, os resultados obtidos em relação aos antivirais foram limitados, pois os efeitos terapêuticos dos compostos não foram avaliados separadamente e a dose administrada neste ensaio não foi descrita, impedindo a comparação dos resultados gerados por outros autores.

Devido ao surto do novo coronavírus SARS-CoV-2, a combinação Lopinavir/Ritonavir mostrou-se atrativa, pois as pesquisas anteriores têm evidenciado resultados promissores para o tratamento de infecções causadas por coronavírus. Wang et al. (41), reportaram o progresso clínico e a terapia de quatro pacientes, infectados com SARS-CoV-2, admitidos no Centro Clínico de Saúde Pública de Xangai. Os pacientes foram medicados com Lopinavir (400 mg)/Ritonavir (100 mg), Umifenovir (Arbidol - 0,2 g), e cápsula medicinal chinesa - Shufeng Jiedu Capsule - (2,08 g) e demonstraram melhoras significativas no quadro de pneumonia e sintomas associados (41).

Lim et al. (42) relataram o caso de uma paciente coreana diagnosticada com COVID19, apresentando sintomas respiratórios leves e febre intermitente no início da internação, porém, com evolução para sinais de pneumonia, em tomografia computadorizada, no sexto dia. Houve a administração de dois comprimidos de Lopinavir (200 mg) / Ritonavir $(50 \mathrm{mg})$ a partir do oitavo dia de internação e no dia seguinte foi observado uma diminuição da carga viral até sua completa deleção, além de melhora dos sintomas clínicos da paciente (42). Apesar de tais dados, a melhora clínica e a carga viral reduzida podem ser relacionadas ao processo de cura natural da doença e não com a administração do medicamento.

Além disso, Yan et al. (43) analisaram os fatores associados à replicação do RNA de SARS-CoV-2 intracelular e sua capacidade de infectar outras células posteriormente, em pacientes tratados previamente com Lopinavir/Ritonavir. Esse estudo, foi realizado em um hospital na província de Hubei, na China, abrangendo 120 pacientes internados com COVID-19, sendo que 78 pacientes receberam Lopinavir (400 mg) e Ritonavir (100 mg) e 42 não receberam tratamento. Foi observado que a duração de detecção do RNA viral nos pacientes que fizeram o tratamento foi menor ( 22 dias) do que os pacientes que não fizeram o tratamento (28,5 dias), para mais, o aumento da carga viral estava diretamente relacionado à piora do quadro clínico. Por outro lado, observaram que somente o uso precoce de Lopinavir e Ritonavir ( $<10$ dias após início dos sintomas) poderia reduzir a 
capacidade de multiplicação e infecção de outras células do hospedeiro (43).

Zuo et al. (44), também, propuseram a associação LPV/r + Interferon- $\alpha$, como um tratamento capaz de promover a redução no tempo em que o vírus SARS-CoV-2 infecta as células do hospedeiro, multiplica-se e, consequentemente, aumentar a carga viral nas amostras clínicas dos pacientes. Neste estudo transversal retrospectivo, realizado em dois hospitais em Anhui (China), após análise dos prontuários de 181 pacientes infectados com SARS-CoV-2, estabeleceram uma associação entre o tempo de replicação do RNA e o quadro clínico dos pacientes, concluindo que o início precoce da terapia combinada poderia ajudar na diminuição do tempo de replicação do SARS-CoV-2 (44), semelhante ao proposto nos estudos conduzidos por Yan et al. (43) e Klement-Frutos et al. (46).

Em um estudo de fase dois, prospectivo, aberto e randomizado, Hung et al. (45), avaliaram a eficácia e segurança da combinação Interferon- $\beta$, Lopinavir/Ritonavir e Ribavirina para tratamento de pacientes hospitalizados com COVID-19 em seis hospitais de Hong Kong. Desse modo, 127 pacientes foram recrutados, para compor dois grupos experimentais: tratamento por 14 dias com Lopinavir/Ritonavir $(400 \mathrm{mg} / 100 \mathrm{mg})+$ Ribavirina ( $400 \mathrm{mg}$ ) a cada 12 horas e três doses de 8 milhões de unidades internacionais de interferon- $\beta-1 b$, em dias alternados; e, tratamento somente com Lopinavir/Ritonavir (400 mg/ $100 \mathrm{mg}$ ) a cada 12 horas, em um mesmo período. Em seus resultados, observaram que os pacientes que receberam terapia antiviral tripla obtiveram resultados positivos superiores em relação ao outro grupo, como alívio dos sintomas e permanência hospitalar (45)

Cabe ressaltar que, mesmo que a terapia proposta para a associação Lopinavir e Ritonavir não seja, na maioria dos casos, avaliada isoladamente, pode-se inferir que eles contribuam de maneira inequívoca para o aumento da eficácia das terapêuticas avaliadas nos estudos supracitados. Inclusive pelo fato de que os estudos que associam a outros fármacos são ainda pouco explorados quanto a atividade antiviral no combate a coronavírus em geral.

Sendo assim, Klement-Frutos et al. (46), relataram o caso de um paciente infectado com SARS-COV2 em estado leve, no qual obtiveram negativação da carga viral na amostra de $s w a b$ nasofaríngeo, após tratamento de seis dias com 400 mg de Lopinavir e $100 \mathrm{mg}$ de Ritonavir. Por outro lado, a amostra de escarro deste paciente ainda apresentava RNA viral após o $14^{\circ}$ dia de tratamento. Em conclusão, os autores sugerem que o tratamento com Lopinavir/Ritonavir poderia ser eficaz em pacientes não graves de modo que diminuiria a carga viral do hospedeiro em amostras nasofaríngeas (46).

Cao et al. (47), realizaram um estudo randomizado no Hospital Jin Yin-Tan, Wuhan (China), que envolveu 199 pacientes internados com infecção confirmada por SARS$\mathrm{CoV}-2$. Aleatoriamente, os pacientes foram divididos em dois grupos, o primeiro fez uso de terapia envolvendo Lopinavir/Ritonvir (400 mg e $100 \mathrm{mg}$, por via oral, duas vezes ao dia) mais tratamento padrão e o segundo grupo fez uso somente de terapia padrão (oxigênio suplementar, ventilação não invasiva e invasiva, antibióticos, suporte vasopressor, terapia de substituição renal e oxigenação por membrana extracorpórea). Em seus resultados, verificaram que o grupo cuja terapia foi suplementada com Lopinavir/Ritonavir apresentou resultados semelhantes ao grupo controle, ou seja, sem diferença no tempo de melhora clínica e com incremento de eventos adversos gastrointestinais (47).

Por outro lado, o mesmo estudo reportou que além de apresentar menos complicações após a alta, os pacientes tiveram uma estadia na unidade de terapia intensiva mais curta e uma leve redução no número de mortes (19.2\% versus $25.0 \%)$. Além disso, os autores esclarecem que a porcentagem de RNA viral detectável entre os grupos e durante o período avaliado não foram significativamente diferentes, variando de $34,5 \%$ no quinto 
dia até $60,3 \%$ no $28^{\circ}$ dia de tratamento com a associação de antivirais (47). Neste sentido, é importante reforçar que o diagnóstico desta infecção é realizado através de um método molecular (RT-PCR), baseado na amplificação de RNA viral, o qual não reflete necessariamente a presença de SARS-CoV-2 viável, podendo ser o resultado da atividade antiviral já executada frente ao patógeno. Esta inquietação poderia ser solucionada se os pesquisadores tivessem avaliado a capacidade destes pacientes graves, em transmitir o vírus após a alta e recuperação.

Cabe ressaltar, ainda, a discussão proposta por Baden et al. (48), sobre os resultados encontrados no estudo de Cao et al. (47), onde ele destaca que a população escolhida pelos pesquisadores já apresentavam uma perda considerável da função pulmonar, a qual culminou com a morte de $25 \%$ dos pacientes recrutados para o grupo controle, além do que, a concentração de Lopinavir capaz de atuar frente a SARS-CoV-2 ainda não está bem estabelecida, e neste estudo pode não ter sido suficientemente alta (foram utilizadas duas doses diárias de $400 \mathrm{mg}$ por 14 dias) para alcançar as concentrações séricas necessárias para manter a atividade do fármaco em tecidos infectados (48). Fato esse, respaldado pela baixa biodisponibilidade oral e excessiva metabolização deste fármaco pelo citocromo $\mathrm{P} 450$, e que culmina com a sua administração conjunta com doses eficazes de Ritonavir.

Dessa forma, a associação entre os dois inibidores de proteases, Lopinavir/Ritonavir, se complementam frente à replicação viral, podendo ser destacada como uma opção atraente no combate a essas grandes epidemias que tem emergido mundialmente. Isso se deve ao fato de que os fármacos já possuem uma descrição quanto aos níveis de segurança de seu uso, perfil toxicológico, doses e efeitos adversos superando, assim, muitas das dificuldades de inserção no mercado farmacêutico atual. Dessa forma, podem ser redirecionados para avaliação de seus efeitos e eficácia em ensaios clínicos adequados (Fase III) e, se obtiverem resultados promissores e seguros, poderão posteriormente serem incluídos em protocolos e prescritos como uma alternativa terapêutica à COVID-19.

\section{Considerações Finais}

Desde dezembro de 2019 até os dias atuais, a população mundial tem sido afligida pelo novo vírus SARS-CoV-2, causador de milhares de mortes. Diante desse quadro, os governos mundiais, além da OMS, lutam diariamente para orientar os indivíduos frente a pandemia, como o isolamento social, bem como buscam medidas eficazes para manejo de pacientes acometidos com a COVID-19. Além disso, é imprescindível que haja buscas constantes de compostos ativos promissores para o tratamento da doença, por esse motivo, é necessário um esforço conjunto das nações para que esse objetivo seja alcançado em menor tempo, assim o redirecionamento de compostos já conhecidos pode ser uma boa estratégia.

O composto pró-fármaco, Remdesivir, demonstrou um alto potencial de atividade antiviral, in vitro e in vivo, em doenças causadas por coronavírus, como SARS e MERS. Tal feito, tornou-o um possível inibidor do vírus da COVID-19 e assim recebeu destaque em várias pesquisas e, atualmente, estudos clínicos randomizados. De acordo com os estudos encontrados que fizeram o uso de Remdesivir, o composto comporta-se de maneira positiva frente ao vírus e a doença. Entretanto, há obstáculos a serem vencidos, como maiores investimentos governamentais em pesquisas e estudos clínicos que possam esclarecer melhor os efeitos positivos, mecanismos e segurança do Remdesivir, quando utilizado para tratamento da COVID-19.

Além disso, os inibidores de enzimas Lopinavir e Ritonavir também foram alvo de pesquisas, diante de doenças passadas. Os fármacos, inicialmente desenvolvidos para 0 
tratamento de pacientes com HIV, foram avaliados de maneira individual e combinada (Lopinavir/Ritonavir) em SARS e MERS, bem como associado a outros fármacos. Nesse sentido, foram redirecionados para estudos envolvendo SARS-CoV-2 e apresentaram resultados questionáveis diante da doença, assim, há necessidade de mais estudos clínicos que avaliem sua atividade individual e a associação a outros medicamentos.

Diante do cenário mundial, em que há diariamente um aumento do número de indivíduos infectados e óbitos, há urgência em criar diretrizes e estratégias para o combate da COVID-19. Em suma, os órgãos governamentais, além de orientar a população e investir em suporte hospitalar devem se envolver em pesquisas e estudos que possam demonstrar evidências científicas em relação à eficiência e aos efeitos de possíveis medicamentos utilizados no tratamento da COVID-19. Nesse sentido, são necessários mais estudos clínicos e experimentais para que outros antivirais mereçam destaque maior, como o Remdesivir, aumentando o rol de possibilidades para o combate da COVID-19.

\section{Referências}

1. Burrell CJ, Howard CR, Murphy FA. Fenner and White's medical virology.2017; 5. Ed; cap. 31; 437-446.

2. Kuiken, T, Fouchier, RA, Schutten M, Rimmelzwaan GF, Van Amerongen G, van Riel D, et al. Newly discovered coronavirus as the primary cause of severe acute respiratory syndrome. The Lancet 2003; 362(9380): 263-270.

3. de Groot RJ, Baker SC, Baric RS, Brown CS, Drosten C, Enjuanes L, et al. Commentary: Middle East respiratory syndrome coronavirus (MERS-CoV): announcement of the Coronavirus Study Group. Journal of virology 2003; 87(14):7790-7792.

4. Zaki AM, Van Boheemen S, Bestebroer TM, Osterhaus AD, Fouchier RA. Isolation of a novel coronavirus from a man with pneumonia in Saudi Arabia. New England Journal of Medicine 2012; 367(19): 1814-1820. Erratum in: N Engl J Med 2013; 396(4):394.

5. Zhu N, Zhang D, Wang W, Li X, Yang B, Song J, et al. A novel coronavirus from patients with pneumonia in China, 2019. New England Journal of Medicine 2020; 382(8): 727-733.

6. Huang C, Wang Y, Li X, Ren L, Zhao J, Hu Y, et al.Clinical features of patients infected with 2019 novel coronavirus in Wuhan, China. The Lancet 2020; 395(10223): 497-506. Erratum in: Lancet. 2020;

7. Gorbalenya AE, Baker SC, Baric RS, of the International, CSG.The species Severe acute respiratory syndrome-related coronavirus: classifying 2019-nCoV and naming it SARS-CoV-2. The Nat Microbiol 2020; 5: 536-544.

8. World Health Organization (WHO). WHO Coronavirus Disease (COVID-19) Dashboard. Disponível em: https://covid19.who.int/ [Acesso em 2 de junho de 2020]

9. Wang D, Hu B, Hu C, Zhu F, Liu X, Zhang J, et al. Clinical characteristics of 138 hospitalized patients with 2019 novel coronavirus-infected pneumonia in Wuhan, China. Jama 2020; 323(11): 1061-1069.

10. Calvo C, López-Hortelano MG, de Carlos Vicente JC, Martínez JLV, de trabajo de la Asociación G, et al. Recomendaciones sobre el manejo clínico de la infección por el «nuevo coronavirus» SARS-CoV2. Grupo de trabajo de la Asociación Española de Pediatría (AEP). In Anales de Pediatría. Elsevier Doyma. 2020; 92(4): 241.e1-241.e11.

11. Li T. Diagnosis and clinical management of severe acute respiratory syndrome Coronavirus 2 (SARSCoV-2) infection: an operational recommendation of Peking Union Medical College Hospital (V2. 0) Working Group of 2019 Novel Coronavirus, Peking Union Medical College Hospital. Emerging Microbes \& Infections 2020; 9(1):582-585.

12. Ministério da Saúde. DIRETRIZES PARA DIAGNÓSTICO E TRATAMENTO DA COVID-19. Disponível em: https://portalarquivos.saude.gov.br/images/pdf/2020/May/21/Nota-informativaOrientações-para-manuseio-medicamentoso-precoce-de-pacientes-com-diagn--stico-da-COVID19.pdf [Acesso em 7 de junho de 2020]

13. Guo YR, Cao QD, Hong ZS, Tan YY, Chen SD, Jin HJ, et al. The origin, transmission and clinical therapies on coronavirus disease 2019 (COVID-19) outbreak - an update on the status. Military Medical Research 2020; 7(1):1-10. 
14. Warren T K., Jordan R, Lo MK, Ray AS, Mackman RL., Soloveva V, et al. Therapeutic efficacy of the small molecule GS-5734 against Ebola virus in rhesus monkeys. Nature 2016; 531(7594):381-385. Erratum in: ACS Chem Biol. 2016; 11(5):1463.

15. de Wit E, Feldmann F, Cronin J, Jordan R, Okumura A, Thomas T, et al. Prophylactic and therapeutic remdesivir (GS-5734) treatment in the rhesus macaque model of MERS-CoV infection. Proceedings of the National Academy of Sciences 2020; 117(12): 6771-6776.

16. Sheahan TP, Sims AC, Leist SR, Schäfer A, Won J, Brown AJ, et al. Comparative therapeutic efficacy of remdesivir and combination lopinavir, ritonavir, and interferon beta against MERS-CoV. Nature Communications 2020; 11(1):1-14.

17. Minskaia E, Hertzig T, Gorbalenya AE, Campanacci V, Cambillau C, Canard B, et al.Discovery of an RNA virus $3^{\prime} \rightarrow 5^{\prime}$ exoribonuclease that is critically involved in coronavirus RNA synthesis. Proceedings of the National Academy of Sciences 2006; 103(13): 5108-5113

18. Shannon A, Le NTT, Selisko B, Eydoux C, Alvarez K, Guillemot JC., et al. Remdesivir and SARSCoV-2: Structural requirements at both $\mathrm{nsp} 12 \mathrm{RdRp}$ and $\mathrm{nsp} 14$ Exonuclease active-sites. Antiviral Research 2020; 178; 104793.

19. Wang M, Cao R, Zhang L, Yang X, Liu J, Xu M, et al. Remdesivir and chloroquine effectively inhibit the recently emerged novel coronavirus (2019-nCoV) in vitro. Cell research 2020; 30(3): 269-271.

20. Beck BR., Shin B, Choi Y, Park S, Kang K. Predicting commercially available antiviral drugs that may act on the novel coronavirus (2019-nCoV), through a drug-target interaction deep learning model. bioRxiv Computat Struct Biotechnol J 2020; 18: 784-790.

21. Grein J, Ohmagari N, Shin D, Diaz G, Asperges E, Castagna A, et al. Compassionate use of remdesivir for patients with severe Covid-19. New England Journal of Medicine 2020. Doi: 10.1056/NEJMoa2007016. [Epub ahead of print].

22. Holshue ML, DeBolt C, Lindquist S, Lofy KH, Wiesman J, Bruce H, et al. First case of 2019 novel coronavirus in the United States. New England Journal of Medicine 2020; 382(10): 929-36.

23. Durante-Mangoni, E, Andini R, Bertolino L, Mele F, Florio L., Murino P et al. Early experience with remdesivir in SARS-CoV-2 pneumonia. Infection, 1. 2020; https://doi.org/10.1007/s15010-02001448-X

24. ClinicalTrials.gov. Study to Evaluate the Safety and Antiviral Activity of Remdesivir (GS-5734 ${ }^{\mathrm{TM}}$ ) in Participants With Severe Coronavirus Disease (COVID-19). Disponível em: https://clinicaltrials.gov/ct2/show/NCT04292899. [Acesso em 7 de junho de 2020]

25. Wang, Y, Zhang D, Du G, Du R, Zhao J, Jin, Y et al. Remdesivir in adults with severe COVID-19: a randomised, double-blind, placebo-controlled, multicentre trial. The Lancet 2020; 395(10236): 15691578

26. ClinicalTrials.gov Adaptive COVID-19 Treatment Trial (ACTT). Disponível em: https://clinicaltrials.gov/ct2/show/NCT04280705. [Acesso em 7 de junho de 2020]

27. Goldman JD, Lye DC, Hui DS, Marks KM., Bruno R, Montejano R, et al. Remdesivir for 5 or 10 days in patients with severe Covid-19. New England Journal of Medicine 2020; doi: 10.1056/NEJMoa2015301

28. Dhama K, Sharun K, Tiwari R, Sircar S, Bhat S, Malik YS, et al. Coronavirus Disease 2019 - COVID19. Preprints. 2020; 2020030001.

29. Hsu A, Granneman GR, Bertz RJ. Ritonavir. Clinical pharmacokinetics and interactions with other anti-HIV agents. Clin Pharmacokinet 1998; 35(4): 275-291.

30. Molla A, Korneyeva M, Gao Q, Vasavanonda S, Schipper PJ, Mo HM, et al. Ordered accumulation of mutations in the HIV protease confers resistance to ritonavir. Nature medicine 1996; 2(7):760-766.

31. Cvetkovic RS, Goa KL Lopinavir / Ritonavir. Drugs: a review of its use in the management of HIV infection 2003; 63(8):769-802

32. Wu CY, Jan JT, Ma SH, Kuo CJ, Juan HF, Cheng, YSE, et al. Small molecules targeting severe acute respiratory syndrome human coronavirus. Proceedings of the National Academy of Sciences 2004; 101(27): 10012-10017.

33. de Wilde AH, Jochmans D, Posthuma CC, Zevenhoven-Dobbe JC, van Nieuwkoop S, Bestebroer TM, et al. Screening of an FDA-approved compound library identifies four small-molecule inhibitors of Middle East respiratory syndrome coronavirus replication in cell culture. Antimicrobial agents and chemotherapy $2014 ; 58(8): 4875-4884$. 
34. Dayer MR, Taleb-Gassabi S, Dayer MS.Lopinavir; A Potent Drug against Coronavirus Infection: Insight from Molecular Docking Study. Archives of Clinical Infectious Diseases 2017; 12(4).

35. Oldfield V, Plosker GL. Lopinavir / Ritonavir. Drugs: a review of its use in the management of HIV infection. Drugs 2006; 66(9): 1275-99.

36. Sheahan, TP, Sims, AC, Leist, SR et al. Comparative therapeutic efficacy of remdesivir and combination lopinavir, ritonavir, and interferon beta against MERS-CoV. Nat Communications 2020; 11(1): 222.

37. Chu CM, Cheng VC, Hung IF, et al. Grupo HUSS. Role of lopinavir/ritonavir in the treatment of SARS: initial virological and clinical findings. Thorax 2004; 59(3): 252-256.

38. Kim UJ, Won EJ, Kee SJ, Jung SI, Jang HC. Case report Combination therapy with lopinavir/ritonavir, ribavirin and interferon- $\alpha$ for Middle East respiratory syndrome. Antiviral therapy 2016; 21: 455-459.

39. Kang CK, Seong MW, Choi SJ, Kim TS, Choe PG, Song SH, et al. In vitro activity of lopinavir/ritonavir and hydroxychloroquine against severe acute respiratory syndrome coronavirus 2 at concentrations achievable by usual doses. The Korean Journal of Internal Medicine 2020.

40. Wu J, Li W, Shi X, Chen Z, Jiang B, Liu J, et al. Early antiviral treatment contributes to alleviate the severity and improve the prognosis of patients with novel coronavirus disease (COVID-19). 2020; 32220033.

41. Wang Z, Chen X, Lu Y, Chen F, Zhang W. Clinical characteristics and therapeutic procedure for four cases with 2019 novel coronavirus pneumonia receiving combined Chinese and Western medicine treatment. Bioscience Trends 2020; 14(1):64-68. Erratum in: Biosci Trends. 2020; 14(1):E1.

42. Lim J, Jeon S, Shin HY, Kim MJ, Seong YM, Lee WJ et al. Case of the index patient who caused tertiary transmission of coronavirus disease 2019 in Korea: The application of lopinavir/ritonavir for the treatment of COVID-19 pneumonia monitored by quantitative RT-PCR. Journal of Korean Medical Science. 2020; 35(6): e79.

43. Yan D, Liu XY, Zhu YN, Huang L, Dan BT, Zhang GJ, Gao YH. Factors associated with prolonged viral shedding and impact of Lopinavir/Ritonavir treatment in hospitalised non-critically ill patients with SARS-CoV-2 infection. European Respiratory Journal 2020; 2000799.

44. Zuo Y, Liu Y, Zhong Q, Zhang K, Xu Y, Wang Z. Lopinavir/ritonavir and interferon combination therapy may help shorten the duration of viral shedding in patients with COVID-19: a retrospective study in two designated hospitals in Anhui, China. Journal of Medical Virology. 2020; doi: 10.1002/jmv.26127

45. Hung IFN, Lung KC, Tso EYK, Liu R, Chung TWH, Chu MY et al. Triple combination of interferon beta-1b, lopinavir-ritonavir, and ribavirin in the treatment of patients admitted to hospital with COVID19: an open-label, randomised, phase 2 trial. The Lancet. 2020; 395(10238): 1695-1704

46. Klement-Frutos E, Burrel S, Peytavin G, et al. Early administration of ritonavir-boosted lopinavir could prevent severe COVID-19 [published online ahead of print, 2020 May 27]. J Infect. 2020; S01634453(20): 30318-2.

47. Cao B, Wang Y, Wen D, Liu W, Wang J, Fan G, et al. A trial of lopinavir-ritonavir in adults hospitalized with severe Covid-19. New England Journal of Medicine 2020; 382:1787-99.

48. Baden LR, Rubin EJ. Covid-19-the search for effective therapy. New England Journal of Medicine 2020;382: 1851-2. 